\section{ULTRASONOGRAPHY: a new beginning with international open access}

JEONG-SIK YU

Editor-in-Chief ULTRASONOGRAPHY

During the last decades, along with the great strides in diagnostic medicine and intervention, ultrasound technology has grown and global standards in research publication have been raised. After many zealous discussions and debates on the present and future academic rigor and global status of the Korean Society of Ultrasound in Medicine (KSUM), the Board of Directors of KSUM decided to convert our 32-year-old domestic journal, the Journal of Korean Society of Ultrasound in Medicine, to an international publication. For better accessibility, our renewed journal, Ultrasonography, is now being published in English and with open access, that is, with the full text of all articles freely available online. Online access to the text from past issues of the journal is also available to maintain a record of valuable research from the past.

Ultrasonography is primarily dedicated to original research encompassing all of the subspecialties of ultrasound in medicine. Along with original papers, the journal also contains invited review articles about current technological or clinical issues, pictorial essays presenting intuitive educational materials, and a few select case reports having an important impact on patient management. Ultrasonography will also serve as a medium for cooperation among physicians and specialists worldwide focusing on various ultrasound technology and disease problems.

We have established the Editorial Board, comprising an international group of outstanding scientists, to meet global standards in the process of peer reviewing submitted papers as well as collaborating across borders. We will try to complete the review process and inform authors of the status of their manuscripts within four to six weeks of submission. I believe that Ultrasonography will grow and will be widely noted in the near future. We envision having many distinguished papers from around the world published in our journal devoted to advances in the field of ultrasound in medicine. On behalf of all the members of the Editorial Board and publication staff, I look forward to receiving a strong range of submissions and contributions from international researchers as well as the members of the KSUM.

Jeong-Sik Yu, MD

Department of Radiology, Gangnam Severance Hospital, Yonsei University College of Medicine, 211 Eonju-ro, Gangnam-gu, Seoul 135-720, Korea Tel: +82-2-2019-3510, Fax: +82-2-3462-5472, E-mail: yjsrad97@yuhs.ac

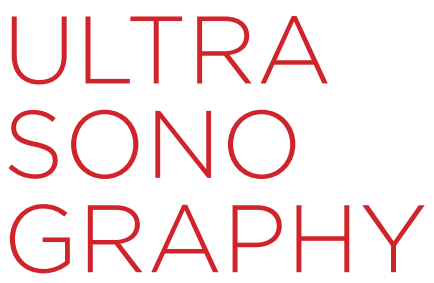

\section{EDITORIAL}

http://dx.doi.org/10.14366/usg.13007 pISSN: 2288-5919 • elSSN: 2288-5943 Ultrasonography 2014;33:1

Received: October 30, 2013

Revised: November 18, 2013

Accepted: November 26, 2013

This is an Open Access article distributed under the terms of the Creative Commons Attribution NonCommercial License (http://creativecommons.org/ licenses/by-nc/3.0/) which permits unrestricted noncommercial use, distribution, and reproduction in any medium, provided the original work is properly cited.

Copyright (c) 2014 Korean Society of Ultrasound in Medicine (KSUM)

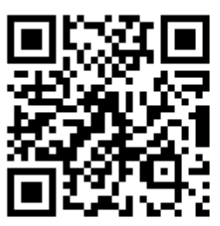

How to cite this article:

Yu JS. ULTRASONOGRAPHY: a new beginning with internation open access. Untrasonography. 2014 Jan;33(1):1. 